\title{
Mundos antagónicos en «Bananos y hombres", de Carmen Lyra ${ }^{1}$
}

\section{(Antagonistic Worlds in "Bananos y hombres," by Carmen Lyra)}

\section{Gineth Tatiana Rivera Cerdas ${ }^{2}$}

Universidad Nacional, Costa Rica

José Enrique Cordero Cordero

Universidad Nacional, Costa Rica

\begin{abstract}
RESUMEN
Se trata de un estudio pormenorizado de temas y perspectivas políticas mostradas en el conjunto de relatos «Bananos y hombres», de Carmen Lyra. Se hace hincapié en el tratamiento de los problemas sociales y políticos de la época en que se escriben esas páginas, y en la perspectiva crítica que se adopta desde la voz narrativa. Con ello, se pone de manifiesto el compromiso político y social que la autora asume como escritora y como intelectual.
\end{abstract}

\begin{abstract}
This is a detailed study of the topics and political perspective evident in the set of short stories "Bananos y hombres," by Carmen Lyra. Emphasis is given to the approach to the social and political problems of the period in which the stories were written, and to the critical perspective which is adopted from the voice of the narrator. Thus, light is shed on the political and social commitment which the author assumes as a writer and as an intellectual.
\end{abstract}

1 Recibido: 24 de abril 2020, aceptado: 25 de agosto 2020.

2 Maestría de Historia Aplicada, UNA. Correo electrónico: gineth7ri@gmail.com

3 Maestría de Historia Aplicada, UNA. Correo electrónico: joseecordero@gmail.com

LETRAS 69 (2021), ISSN 1409-424X; EISSN 2215-4094

DOI: http://dx.doi.org/10.15359/rl.1-69.3

www.revistas.una.ac.cr/index.php/letras 
Palabras clave: narrativa costarricense, Carmen Lyra, capitalismo, enclave bananero

Keywords: Costa Rican narrative, Carmen Lyra, capitalism, banana enclave

De tiempos inmemoriales Que se ha inventado el infierno

Para asustar a los pobres

Con sus castigos eternos

$Y$ el pobre, que es inocente

Con su inocencia creyendo.

VIOLETA PARRA

\section{Carmen Lyra y el realismo social ${ }^{4}$}

Carmen Lyra con su acercamiento al realismo social, fue mentora de intelectuales costarricenses. Adoptaron un compromiso político, como Carlos Luis Fallas, que posteriormente escribió Mamita Yunai ${ }^{5}$. El concepto de compromiso y militancia social alcanzó más espacio entre los escritores del subcontinente. Se generó una tendencia literaria, que rechazó la literatura centrada en la forma y la estética de las palabras, percibida como distracción ociosa de la burguesía. Por ende, se insistió en la funcionalidad de la literatura para la lucha por la liberación de la clase obrera; es decir, la literatura tuvo nuevos cargos, como educar y transmitir nuevos paradigmas políticos, como fue el caso de la literatura marxista ${ }^{6}$. Desde dicha lógica, Grinberg y Mackenbach comprenden la literatura bananera como clave en la construcción de una nación mestiza «desde abajo» en contra de proyectos oligárquico-autoritarios o pequeñoburgueses ${ }^{7}$.

4 Sobre los aspectos sociales y sobre «Bananos y hombres» en particular, puede consultarse también el estudio publicado en Letras de: Flora Ovares y Seidy Araya, «Ensayo y relato en Carmen Lyra», Letras 18-19 (1988): 195-216. (N. de la E.)

5 Arnoldo Mora Rodríguez, «Calufa y el Realismo Social», Comunicación 18 (2009): 8.

6 D. W. Fokkema y Elrud Ibsch, Teorias marxistas de la literatura del siglo XX (Madrid: Catedra, 1981) 123.

7 Valeria Grinberg Pla y Werner Mackenbach, «Banana novel revis(it)ed: etnia, género y espacio», Iberoamericana VI, 23 (2006): 164. 
Este empeño por realizar una literatura comprometida apunta a poner de manifiesto dos mundos antagónicos: la miseria de los trabajadores y la existencia acaudalada de quienes disfrutan de la riqueza producida. Según Rodríguez $^{8}$, se trata de un sistema semiótico de oposiciones fundamentado en una dimensión performativa y de toma de posición crítica: la denuncia como llamado del quehacer literario. «Bananos y hombres» es un conjunto de relatos que su autora reunió y publicó en la revista Repertorio Americano en $1931^{9}$.

\section{«Bananos y hombres»}

Carmen Lyra abre el conjunto de relatos con la narración denominada «Estefanía», al insertar un epígrafe, que nuestra la posición de la autora en torno a las relaciones clasistas y laborales en las compañías bananeras, donde se deshumanizó a la mujer, al hombre y a los infantes, con relaciones de explotación.

Pongo primero bananos que hombres porque en las fincas de banano, la fruta ocupa el primer lugar o más bien el único. En realidad el hombre es una entidad que en esas regiones tiene un valor mínimo y no está en el segundo puesto, sino que va en la cola de los valores que allí se cuentan ${ }^{10}$.

El relato destaca la interposición de la fruta ante la vida humana, desde diferentes ámbitos; como la dignidad, la moral, la ética, entre otras. Se refiere a la capitalización de las relaciones sociales imperantes en un contexto de enclave bananero, donde el hombre se encuentra al final de la cadena de valor. Hay una clara intención en la incorporación del epígrafe: señalar la injusticia y la explotación a

8 Francisco Rodríguez Cascante, Imaginarios utópicos. Filosofía y literatura disidentes en Costa Rica (1904-1945) (San José, Costa Rica: Editorial Universidad de Costa Rica, 2016) 242.

9 Carmen Lyra, «Bananos y hombres», Repertorio Americano XXII, 20-23 (1931). El conjunto lo reprodujeron después Luisa González y Carlos Luis Sáenz, en la biografía Carmen Lyra (San José, Costa Rica: Ministerio de Cultura, Juventud y Deportes, 1972). Los autores de este artículo utilizan la reedición de 1998, de la Editorial de la Universidad Estatal a Distancia. (N. de la E.)

10 González y Sáenz, 37. 
la que están expuestos los trabajadores de los bananales, los cuales, parecen no existir para el gobierno ni para la compañía bananera, a pesar de las luchas sociales que se llevaron adelante en las décadas de 1920 y 1930 en Costa Rica ${ }^{11}$.

Al drama vivido entre los bananales se van incorporando diferentes actores sociales. Estefanía $\mathrm{R}^{12}$, nombre que aparece en una cruz negra en la playa entre Barra del Tortuguero y del Colorado. Lyra acude al uso de una metáfora sobre la procedencia del apellido, «dentro de poco completamente ilegible» indicativo de la naturalización de la muerte en estos lugares, además de que Estefanía R muere en el olvido, como tantas otras mujeres y hombres de los enclaves. Un elemento estético consiste en representar la cruz de color negruzco en la que aparece el nombre. La cruz como símbolo religioso que denota el calvario, es decir, todo el sufrimiento con el que la mujer debe cargar como la sumisión, embarazos, dejar hijos en el camino, violaciones, violencia (física y psicológica) enfermedad y explotación. Por otro lado, la cruz es arrastrada por el mar, lo que simboliza la inmensidad de la mar contrapuesta con el nombre (mujer u hombre), que puede resultar insignificante ante la lógica de explotación del sistema económico de enclave bananero.

Estefanía representa la vida de las mujeres que por diversas razones llegaron a las bananeras. Aquellas descritas como «figuras pálidas, marchitas, tostadas por el sol, las fiebres y la sensualidad del hombre, amoral e inocente como los animales $\rangle^{13}$. Desde el plano narrativo ficcional, la figura de la mujer «anónima» es una excusa para dar a conocer la migración femenina, quien migró desde Guanacaste con un hijo, al cual debió detenerse para regalar; consecutivamente siguió

11 Para un estudio detallado sobre las luchas sociales de las primeras décadas del siglo xx, véase: Carlos Hernández Rodríguez, «Del espontaneísmo a la acciónáles concertada: los trabajadores bananeros de Costa Rica 1900-1955». Revista de historia (Costa Rica) 31 (enero-junio 1995); y Marielos Aguilar Hernández, Costa Rica en el siglo xx: luchas sociales y conquistas laborales (San José, Costa Rica: Editorial Universidad de Costa Rica, 2009).

12 Corresponde al primer capitulo de «Bananos y hombres», que alude al drama que pasaron las mujeres que llegaron a estas economías de enclave bananero.

13 González y Sáenz, 37. 
su viaje, junto a su hija, para ir a dar a los bananales inhóspitos, donde se involucró con hombres por necesidad y posteriormente fue víctima de violación. En ese plano ficcional se abstrae la referencialidad de cómo se remite a una realidad externa a la propia realidad del texto. $\mathrm{Si}$ bien el texto contiene su propia «verdad», también muestra la realidad de las economías de enclave bananero. Siguiendo los planteamientos de Alvarado, dicho entorno se relaciona con los hechos presentados en el cuento, sin que implique una copia de la realidad, sino de una manifestación que se hace evidente en la textualidad y que no es ajena al contexto donde se tiene lugar ${ }^{14}$.

Se alude a la crisis económica del país y sus consecuencias; por ejemplo, el fenómeno de la migración afectó tanto a hombres como a mujeres, quienes se desplazaron en busca de mejores condiciones. En la mayoría de casos no trascendió un sentimiento de esperanza, visible en la textualidad del relato del drama representado en Estefanía R. La autora describe la situación vivida no solo por mujeres que llegaron a las bananeras, sino por las personas en general (hombres, mujeres, niños y niñas).

Desde la intratextualidad de la narración se infieren los procesos históricos relacionados con los movimientos migratorios en Costa Rica a mediados siglo xx, que se originaron del campo a la ciudad, así como entre zonas rurales. Para el caso de Guanacaste, durante el periodo se dieron procesos migratorios, las personas buscaron mejores condiciones de vida. Peters sostiene que el establecimiento de las grandes haciendas ganaderas y el poco empleo existente en Guanacaste provocaron migraciones, como al norte del país ${ }^{15}$, como en el caso de la obra, Estefanía R proveniente de una Guanacaste, región que expulsó a muchas personas que llegaron hasta Limón. Esta «figura anónima», pese a todas las vicisitudes, se convirtió en la cocinera «fiel

14 Óscar Gerardo Alvarado Vega, Literatura e identidad costarricense (San José, Costa Rica: Editorial de la Universidad Estatal a Distancia, 2009) 368.

15 Peters Solórzano Gertrud, «Upala: Paisajes reconstruidos por sus antiguos inmigrantes», Revista de Historia 78 (2018): 33-62. 
al hijo del dueño como un perro». Asumió una posición de vigilante de los bienes de su amo, no está dispuesta a permitir que se pierda ni un céntimo del comisariato, ni consentir que los trabajadores sustraigan absolutamente nada de la finca. La autora expone a esta mujer tan fiel al amo que incluso estaría dispuesta a morir por él. Muestra con su accionar que algunos trabajadores concientizaron su papel subalternizado y los asumieron como positivo o no cuestionaron la explotación a la que fueron sometidos.

Estas actitudes inducen a una lectura más allá de lo intratextual, lo que obliga a ponerla en términos de un diálogo sociedad-texto que comparte una interacción necesaria en el proceso pretendido de significación ${ }^{16}$. Si se toma en cuenta que el mundo intratextual se refiere a la historia que desarrolla el texto, en su proceso de producción, «la verdad» le pertenece solo a ese ámbito literario. Por su parte, lo extratextual son las condiciones alrededor del proceso de producción, es decir, la capacidad del texto de generar significación ${ }^{17}$.

Conviene considerar no solo la pobreza material y espiritual de la mujer en un contexto de enclave bananero, que se demostró en el relato de Estefanía R, la cual se transformó en un producto de la explotación del amo (sistema económico), que a su vez defiende los bienes de sus propios explotadores. Mostrando el proceso de deshumanización a la que es sujeta, ella en su mísera existencia, le custodia la fortuna a su explotador, le da igual que el capataz en cada borrachera la violente físicamente (a ella, a su hija y a su mascota). Además, representa la injusticia de un sistema económico que la hizo migrar por desempleo (Guanacaste) y que la condiciona a la explotación por subsistir en las bananeras (Limón). No hay distinción entre la humillación a una persona o a un animal en una economía de enclave. La diferenciación social es notable cuando la mujer se enfermó y no fue relevante para nadie. No obstante, ella volvió a la bananera; ¿a qué? se cuestiona la autora. El texto denunció las paupérrimas condiciones de vida presentes en

16 Alvarado Vega, 89.

17 Alvarado Vega, 90. 
los enclaves, donde fue necesario una distracción o analgésico social como fue el uso de licor.

Se puede considerar el hecho de que en estos lugares, alejados de toda civilización, el licor era el único medio de distracción y quizá la única escapatoria, desde toda perspectiva repudiable, de los peones y sus familiares para aminorar la deprimencia que produce el medio hostil en que viven ${ }^{18}$.

En los espacios de enclave se acude a la bebida como apaciguadora de los males del hombre. La existencia permeada con la explotación diaria, como a los efectos negativos en la salud, producto del trabajo, tal como le sucedió al personaje Poncho Ortega tras el fuerte golpe que recibió en la rodilla, ante lo cual, la autora cuestiona ¿acaso vale más su rodilla que el banano de United Banana Co ${ }^{19}$. Al presentarse una relación de desvalorización del peón con respecto de la fruta, donde la condición humana no vale, no queda más para el hombre que beber, se emborracha haciendo caso omiso de las campañas antialcohólicas hechas por el Estado.

La Compañía procuró tener licor en los comisariatos, porque la vida de los peones sería sinél insoportable. Braudel señalólos beneficios que se pueden obtener del consumo de licor, haciendo referencia al accionar de ingleses y franceses en las colonias de América de finales del siglo xvI: «No hay mejor manera de crearles una nueva necesidad que les obligue a reconocer su dependencia forzosa de nosotros $\rangle^{20}$. El consumo de sustancias alcohólicas se inserta en el mundo laboral de

18 Francisco Vega Ramírez, «Perspectivas narrativas sobre el tema del banano en tres obras costarricenses». Tesis de Licenciatura en Literatura y Lingüística con énfasis en Español (Heredia, Universidad Nacional, 1998. 37.

19 González y Sáenz, 42.

20 Fernand Braudel. Bebidas y excitantes (Madrid: Alianza Cien, 1994) 39. Su autor desarrolla un capitulo en el que analiza como los ingleses y franceses principalmente, utilizaron las bebidas alcoholicas para mantener bajo su dominio las colonias americanas, sin que éstos se revelaran. Muestra, además, que algunos de los imperios indígenas anterioriores a la llegada de los europeos ya tenían tradición en el consumo de alcohol. 
aquellos que trabajaban para empresas extranjeras, desde que estas empezaron a tener relaciones con el Estado costarricense ${ }^{21}$.

Se describe el paisaje en «Nochebuena» ${ }^{22}$; desde su inicio con el epígrafe posicionó como elemento narrativo, la condición social diferenciada entre la opulencia y la miseria entorno a la actividad bananera. Lo importante es la cantidad de fruta que se debe recolectar: «En las fincas de banano se le guardan más consideraciones a una mata de banano que a un peón» ${ }^{23}$. Se insiste en la desvalorización humana como eje de una economía de enclave desarrollada en la década de 1930, por Honduras, Costa Rica y Panamá, bajo el dominio de la United Fruit Company (UFCo).

La UFCo diseminó el espíritu y las prácticas del liberalismo capitalista en América Central y en partes del Caribe (Jamaica, Cuba y República Dominicana).

$\mathrm{Su}$ influencia sobre las naciones en las que se estableció fue sencillamente avasalladora y temible a la vez. La referencia a "banana republics" ignora sin duda la complejidad política y la diversidad cultural de estas naciones y es una expresión neocolonialista y devaluadora, tan arrogante y ofensiva como la sentencia de Sam Zemurray acerca de que en Honduras un diputado era más barato que una mula ${ }^{24}$.

21 Como fue en la construcción de Ferrocaril al Atántico de 1870 a 1890, bajo de la administración del empresario Minor Keith, el que trajó trabajadores de Italia, China, Jamaica, entre otras nacionalidades, quienes se entretuvieron con el consumo de alcohol y drogas, tales como ron y opio. La empresa buscó mecanismos para que los trabajadores sobrellevaran la difícil condición del caribe establecieron «la promoción de consumo de drogas entre sus trabajadores, que además de un lucrativo negocio, constituyó otro mecanismo para granjearse la lealtad hacia la empresa. El licor, el tabaco y el opio circulan copiosamente en los campamentos y eran vendidos al crédito a los rabajadores, descontándoseles posterioriomente de sus salarios». Carmen Murillo, Identidades de hierro y humo: la construcción del ferrocarril al Atlántico 1870-1890 (San José, Costa Rica: Editorial Porvenir, 1995) 127.

22 Corresponde a otro capitulo del relato de «Bananos y hombres». En el cual se narra la dualidad de realidades existentes en las fechas de clebracion de la Navidad en los enclaves bananeros, haciendo alusión a la diferenciación social existente.

23 González y Sáenz, 40.

24 Henning Jensen-Pennington, «Sintaxis del espacio y narrativa de poder: arquitectura en Golfito», Reflexiones 91, 1 (2012): 199-206 (201). 
Lyra hace referencia a la noche buena, afirmando que recuerda que esa noche se celebra el nacimiento de Jesús, quien vino a salvar este mundo del pecado ${ }^{25}$. Se hace alusión a que los trabajadores perderán el trabajo realizado por la fruta fue rechazada, por no cumplir con la calidad pedido, a lo que añade, «claro que sí lo tenía, pero había exceso de fruta en los mercados de Estados Unidos y de las alturas vino la orden de rechazar la fruta $»^{26}$. En el relato se señala que la orden la dio «un costarricense yanquizado, de esos que creen que hablar inglés es una gran cosa, recibió dicha orden y se apresuró servil a trasmitirla» ${ }^{27}$, acción por la cual los trabajadores perdieron el trabajo realizado, bajo la lluvia, con las plantaciones inundadas. Por la desilusión y desgaste los trabajadores acuden al licor, donde se embriagan todos, tanto hombres como mujeres y niños.

Desde el plano de lo afectivo, las dinámicas transindividuales del comportamiento humano operan antes de la comprensión racional y existen en un dominio que no es solamente subjetivo ${ }^{28}$. La capacidad de afectar y ser afectados, se presenta como proceso de configuración según Maraña, de nuevas formas de dominación y marginalidad que resultan de la globalización corresponden con pulsiones en el elemento emocional, pasional, desempeñan un papel preponderante, sumado a factores más tradicionales asociados a la formación de consciencia social e imaginarios colectivos ${ }^{29}$.

La figura del costarricense «yanquizado» denota como elemento de crítica o denuncia social a la que acudió Lyra. Por medio de los funcionarios cómplices y permisivos fue que la UFCo logró establecer un control social, económico y productivo en los países en los que se estableció; consecuentemente surgió el peyorativo de «Banana

25 González y Sáenz, 42.

26 González y Sáenz, 42.

27 González y Sáenz, 42.

28 Mabel Moraña, «Postscriptum. El afecto en la caja de herramientas», El lenguaje de las emociones. Afecto y cultura en América Latina, Mabel Moraña e Ignacio Sánchez Prado, eds. (Madrid: Iberoamericana-Vervuert) 313-337 (321).

29 Moraña, 314. 
Republics» en referencia a los países productores de banano, donde no se cuestiona racionalmente por qué fue permisivo. Mientras los trabajadores sufrían de las injusticias y de las condiciones inhumanas en las bananeras, en la ciudad, las ganancias de las fincas servían para que «el padre y el hijo fueran socios del Club Unión, para que la señora anduviera en su carro, su hija se vistiera bien chic y viajara cada año a Europa y a los Estados Unidos a traer vestidos y ropa interior que generaban la envida de sus amigas ${ }^{30}$.

En la "noche buena" cuando se rechazó la fruta, misma en la que llovía y el Reventazón amenazaba con desbordarse, los altos empleados de la United que viven en Limón (en lo que llaman la zona), también celebran su noche buena; es decir, se hace referencia a dos noches antagónicas, una determinada por la explotación laboral inhumana y otra por la opulencia.

Jensen-Pennington sigue los planteamientos de Foucault en relación con las heterotopías del poder (ligado al concepto de panóptico), relativas a la jerarquización del espacio, que demarcan la división del poblado en tres zonas; la zona blanca o americana, la zona amarilla o administrativa y la zona gris u obrera. Son espacios compuestos por elementos entre los cuales existen relaciones -implícitas y explícitas - sujetas a una sintaxis espacial; es decir, un conjunto de reglas que señalan la dirección de los flujos comunicativos y de tránsito, el acceso a los componentes del espacio, la exclusión o segregación respecto a esos componentes, determinando la coordinación entre los niveles de autoridad y la utilización del espacio ${ }^{31}$. En cuanto a la sintaxis espacial, Jensen-Pennington empleó una función clasificatoria de las actividades sociales, como mecanismo que artículo las diferentes dimensiones socioespaciales de la estructura que estableció la UFCo, que Lyra logró plasmar en su narrativa. En esta lógica, cada cosa-persona tiene una localización, donde el espacio se transforma en el lugar que cada quien ocupa en el entramado social y esa posición

30 González y Sáenz, 38.

31 Jensen-Pennington, 155-156. 
constituye una testificación del significado de sus acciones en los procesos de producción y reproducción social ${ }^{32}$. Los espacios clasificatorios son visibilizados en la medida en que los altos empleados adornan sus casas confortables con graciosas coronas de muérdago y plantan arbolitos de Navidad con muchas luces y frutas fantásticas de vidrio, para toda la gente «de bien» de Limón, los machos ${ }^{33}$ han preparado una fiesta en el Amusement Hall. A la fiesta llegó el tico «yanquizado» que había recibido y trasmitido la orden de rechazar la fruta; es un buen hombre, afirma la autora con un matiz sarcástico, padre amante de sus hijos que mira con indiferencia los cuernos que su mujer le pone con los machitos ${ }^{34}$.

Continúa el relato señalando los ligámenes irregulares de diputados con la compañía, que le permitieron obtener contratos de explotación de tierras en el país, señalando que dichos contratos han dejado el destino de Costa Rica en manos de la UFCo, acudiendo a la figura de la metáfora de la navidad, debido a los regalos que se dan en estas fechas. Haciendo alusión a una serie de irregularidades entorno a los contratos de la compañía con el Gobierno, acusaciones que se hicieron en el periódico el Trabajo: «Los bananeros de Boston gobiernan en Costa Rica, el ejecutivo es un simple mandadero de la United Fruit Company» ${ }^{35}$.

En la publicación del periódico se denunció el accionar de la United y los contratos que firma con el Estado. Se expusieron las irregularidades y cómo a la hora de negociar acude a sus «mañas» para lograr cuanto se quiso; como la manipulación de obreros, maestros y funcionarios municipales, a los que compraron con cheques para que fueran al congreso a suplicar la concesión del contrato a la United $^{36}$. Así como lo expone Bourgois, «La UFCo compró influen-

32 Jensen-Pennington, 157.

33 Los terminos macho y machitos es utilizado por la autora para refererse a los norteamericanos trabajadores de UFCo.

34 González y Sáenz., 43.

35 El Trabajo, 21 de enero de 1933, 1.

36 El Trabajo, 1. 
cias, hizo de los gobiernos lo que quiso, echó a los competidores y suprimió al sindicalismo ${ }^{37}$. Es notable la influencia del pensamiento antiimperialista que predominó en el continente americano y que se vieron dinamizados por el APRA (Alianza Popular Revolucionaria Americana $)^{38}$, que se encargó de concentrar una serie de intelectuales que se identificaron con esta corriente, que señaló enfáticamente la intervención del capital extranjero sobre los países del istmo.

En «Niños» se incorpora un sujeto socio-histórico que suele ser invisibilizado: niños y niñas. Aunado al drama que ha venido construyendo a lo largo del relato, pone de manifiesto las vicisitudes de la vida cotidiana de los niños entre los bananales, haciendo hincapié en la serie de enfermedades que los atacan. La comparación entre los niños pálidos y los perrillos flacos y sarnosos que deambulan por el caserío, se fundamenta en su aspecto verdoso, muy morenos, con su estómago enfermo de lombrices, amebas, anquilostomas y sabe Dios cuántos otros monstruos ${ }^{39}$; situación que no distó de la realidad. Botey plantea que Limón y Puntarenas acentuaron una mayor tasa de mortalidad en relación con las otras provincias del país, arguyendo que se generó «producto de las confluencias de las condiciones de relieve, suelo, clima, régimen de lluvias, asistencia medica escasa, condiciones sociales y culturas imperantes $\gg{ }^{40}$. Lyra muestra a niños que no gritan ni saltan; por el contrario, se mueven con lentitud y cuando sonríen dejan ver unas encías vacías, lo cual dan un fondo doloroso del rostro. No obstante, las caras de los niños parecen desconocer la sonrisa, es frecuente y parece ser un retrato bastante fiel al drama que se vivieron

37 Philippe Bourgois, Banano, etnia y lucha social en Centroamérica (San José, Costa Rica: DEI, 1994) 43.

38 El APRA se concretó por el Partido Revolucionario Antiimperialista Latinoamericano, la cual estuvo constituida por trabajadores e intelectuales jóvenes de Latinoamérica, fundada en diciembre de 1924. La organización trabajó por la lucha antiimperialista en América Latina, a partir de un programa de acción política entre los países latinos del continente. Victor Raul Haya de la Torre, El antiimperialismo y el APRA (Lima: Biblioteca del Congreso de Perú, 2010).

39 González y Sáenz, 45.

40 Ana María Botey, «Los actores sociales y la construcción de las políticas de salud del Estado Liberal en Costa Rica (1850-1940)». Tesis de Doctorado Académico en Historia (San José, Costa Rica: Universidad de Costa Rica, 2013) 117. 
en los enclaves bananeros controlados por la UFCo. Así lo detalla la descripción que Lyra realizó sobre la niña Lidia:

Lidia, siete años, debilucha, los parpados hinchados, precoces y perfectamente instruidos en todo lo que se relaciona con el pecado que en las tablas de Moisés ocupa el sexto lugar. Eso sí, ni ella, ni la madre, ni ninguna de esas gentes cree que eso sea pecado. (Yo me pregunto lo que piensan los católicos que hace su Dios con las almas de estas criaturas $)^{41}$.

Esto señala la predominante moral católica en Costa Rica, en el sentido que cuestiona el destino de las almas de los niños que a vista y paciencia de todos sufren de tantas calamidades. Como Lidia, ¿cuántas otras niñas se vieron expuestas al maltrato infantil y sobre todo al abuso físico-sexual? En todo caso, la moral católica sanciona las almas pecadoras, seguramente por lujuriosas, mas no condenaría ni al padre ni al hijo que para poder ser parte del club Unión, hunden en la miseria inhumana a cientos de trabajadores en las bananeras.

Los niños descritos por Lyra son manifestación de un contexto en que el Estado costarricense buscó ampliar su participación en el asunto infantil, regulando aspectos como la salubridad(se hizo hincapié en la disminución la mortalidad infantil), su protección mediante el Patronato Nacional de la Infancia creado en $1930^{42}$ y la formulación del Código de la Infancia en 1932. Mientras tanto, Lyra plasmó las vicisitudes que enfrentaron los infantes en un enclave bananero, los cuales parecen no conocer la sonrisa, afectados por el descuido de los padres, como el caso del niño que tras una caída se le hundió la mollera y lo dejaron «tontico».

Mientras los niños de las bananeras sufrían pobreza y descuido, los altos jerarcas de la UFCo pagaron estudios para que médicos exaltaran los valores nutritivos del banano, promoviendo el consumo de la fruta en los niños estadounidenses (una ironía más en este conflicto de

41 González y Sáenz, 46.

42 Colección de Leyes y Decretos. Ley №39, del 6 de agosto de 1930. 
oposiciones). El discurso promotor del consumo del banano incorporó un quehacer pedagógico, en el sentido que incitó al maestro-maestro a velar por el desarrollo de los niños, así como su buena alimentación, en la que no puede faltar por su puesto el banano. Lo señala categóricamente la autora: «Pero las gentes que trabajan en las fincas de banano dicen que es malo. Bueno, hacen ironía sin saberlo» ${ }^{43}$. Se contrastó la imagen que la compañía utilizó para posicionar el banano en el mercado norteamericano, en que los niños son descritos como sonrientes, sanos y con una mirada golosa. Tal representación se contrapone a la historia de Lidia, culpable del pecado seis de los mandamientos de Moisés (ligado con la sexualidad y la fornicación) o con la del niño que se le hundió la mollera, o con cualquier menor de estas zonas bananeras, donde se produce ese nutritivo y esencial alimento para otros niños y niñas.

Lyra continuó poniendo en evidencia las diferencias de las personas que transcurren por el Atlántico; en el relato «Río arriba» logra una descripción de dos mundos antagónicos: por un lado, los trabajadores de la bananera; por otro, el jefe del Resguardo. Ambos mundos coinciden en la lancha denominada El Parismina que realiza un viaje semanal. Debe ser por eso que coinciden; es decir, no hay muchas opciones para movilizarse, tanto así que un alto jerarca debe viajar con el «mísero vulgo». La autora marca la diferenciación de una familia que emigra a otra finca. La descripción detona la explotación y las paupérrimas condiciones en las que han trascurrido sus vidas entre las bananeras, con calificativos como: un hombre de edad indefinible, seco, alto, encorvado; el clima ardiente, el paludismo y el alcohol lo han retorcido como retuerce el fuego una rama. La mujer y los chiquillos son presentados como anémicos, raquíticos, hinchados, estos niños que no han probado más leche que la materna, los cuales emigran con todos sus bienes, unas ollas viejas y unos trapos ${ }^{44}$.

43 González y Sáenz, 48.

44 González y Sáenz, 49. 
Mientras tanto, en la lancha que lleva a bordo miseria humana y residuos de la explotación capitalista, se encuentra un joven de San José que por tráfico de influencias familiares fue nombrado jefe de Resguardo, tiene cara de comemaíz, criatura inútil que lo único que sabe hacer es bailar bien y beber. Se describe su aspecto como aquel que usa zapatos bajos, medias de seda rayadas, su charla insustancial y su pelo peinado hacia atrás como los intelectuales cursis; desentona con el pútrido ambiente en navegación; por lo tanto, recibe todas las miradas, cual si fuera aretes, collares o cualquier otro adorno de joyería barata en las urnas de los comisariatos. Es decir, la imagen del joven funcionario aburguesado contrasta con el desfile de miseria que representa a los trabajadores de la bananera. Ese desfile continúa al pasar la lancha recogiendo pasajeros en la hacienda Santa María, donde se encuentran con un preso custodiado por dos guardas, unas mujeres jóvenes con paludismo y sífilis que van para el Hospital San Juan de Dios en San José, otro hombre acompañado de una mujer, pues sufrió un accidente laboral, en el que se golpeó fuertemente el pecho y una pierna al cargar bananos al lanchón de la finca. Al respecto se narra que cuando se golpeó nadie le prestó ayuda; precisaba cargar la fruta, y después el dueño de la finca no tuvo tiempo de ocuparse del asunto. ¿Acaso los hombres enfermos cuentan en las fincas de banano ${ }^{45}$ donde la legislación alcanzada por la lucha de la clase obrera no tiene mucho impacto en el enclave, como fue la Ley de accidentes de trabajo aprobada el 31 de enero de 1925, a amparó tanto a los trabajadores industriales como agrícolas ${ }^{46}$.

La autora señala que el Hospital San Juan de Dios se ha convertido en un desaguadero de toda esa gente palúdica, tuberculosa y sifilítica que sale de las fincas en donde se cultiva el banano, haciendo evidente la demanda en dos sentidos. Primero la pasividad de la sociedad y del gobierno, ante la gran cantidad de personas que llegan con enfermedades por el nivel de explotación y las malas condiciones al

45 González y Sáenz, 50.

46 Colección de Leyes y decretos, decreto 53, 31 de enero 1925. 
que se expone en las plantaciones; segundo, el costo social de producir bananos, en el sentido que representó un alto costo social y de salud.

Es indiscutible que la creciente oposición a la influencia estadounidense y especialmente frente a las compañías bananeras se fortaleció en la sociedad costarricense a finales de la década de 1920, no sólo en los medios de comunicación como Repertorio Americano, sino también cuando se fundó en San José el Centro APRA, que en seguida pasó a ser la Sociedad de Estudios Económicos que dirigió Joaquín García Monge; igualmente la Liga Cívica que correspondió a una filial de la Liga Anti-imperialista de las Américas y del comité pro-Sandino, todos estos grupos impulsaron manifestaciones públicas contra los monopolios extranjeros ${ }^{47}$.Además, incorpora la doble moral católica en el sentido que los pacientes que se contagiaron de sífilis serán atendidos por las hermanas de la caridad, las cuales echarán en cara su liviandad al ver la mueca de dolor al inyectar la carne pecadora. Claro que no las curarán los domingos o días de fiesta religiosa por tratarse de enfermedades relacionadas con el pecado, sin que se cuestione por qué estas personas sufren tales males, sino que se juzgan, por lo que debe sumársele a la lista de aflicciones que rodean su vida desde la llega a las bananeras, la explotación laboral, las condiciones insalubres, agresiones, pobreza, desnutrición y ahora pecadoras.

Por último, incluye en el texto un acto cometido por un peón que parecía un santo, procedente de Rivas, descrito como muy pasivo, tranquilo, de unos 35 años. En el momento de su llegada se puso a enseñarle a leer y escribir a los niños, les leía cuentos, tenía una serie de habilidades que le hicieron ganar el aprecio de las personas que vivían en las fincas. Sin embargo, un día lo arrestan por haber degollado a una agente de policía de San Alberto. Se relatan las causas que llevaron a aquel pacífico hombre a cometer tal acto, al percatarse de que el agente se había aliado con un negro al que llaman

47 Jussi Pakkasvirta, ¿Un continente, una nación? Intelectuales latinoamericanos, comunidad politica y las revistas culturales en Costa Rica y el Perú (1919-1930) (San José, Costa Rica: Ediorial Universidad de Costa Rica, 1997) 160. 
el «Cariador» y los días de paga, cuando los peones tomaban licor, el agente les echaba al Cariador para que les buscara pleito, para así poder arrestarlos y cobrar una multa a cambio de liberarlos. Es decir, el peón que parecía un santo se percató de la estrategia que empleó el agente para aprovecharse de los trabajadores y sacarles los poco que les quedaba del salario, como si no les bastara con la explotación a la que los exponía la compañía, sino que también el propio Estado representado por el agente de policía, contribuyeron hacer más miserable la vida de aquellas personas.

Lyra acude a un tratamiento irónico a lo largo del relato que presenta la realidad en torno a la actividad bananera, como el contraste de la riqueza que produce la fruta (para algunos) y para los que directamente están relacionados con el producto, que lejos de generarles riqueza les ocasiona tristeza, miseria, dificultades (sociales, económicas, salud) y humillaciones como parte de la deshumanización a la que se ven enfrentados, como en el caso del personaje Ignacio Parrales, que lo convirtió en asesino.

A lo largo del relato se indican dos espacios o estratos sociales bien diferenciados; los opresores extranjeros-nacionales por un lado y los oprimidos por otro; los primeros, opresores que viven en la opulencia generada por la opresión. Aunque los opresores nacionales se ven expuestos a la degradación moral por parte de los extranjeros al tener que omitir que sus mujeres sean objetos de servicios a los «machos».

\section{Conclusiones}

El análisis distingue que, mediante la implementación de esta representación estética del mundo bananero, se planteó la denuncia de un proceso invisibilizado por los modelos representacionales predominantes en el pensamiento patriarcal liberal. Desde una práctica literaria marxista, buscó el sentido de la misma en el compromiso y la militancia, como elemento liberador de las clases explotadas. Además, el contexto histórico de las economías de enclave bananero 
en Centroamérica y en especial de Costa Rica, se alude a la voracidad con que este tipo de economía afecta a las clases trabajadoras principalmente, la marginalidad complaciente del Estado y la sociedad para con la región atlántica.

La obra lanza una mirada detallada de los enclaves y el costo social que implicó, cuestiones que se señalaron desde inicios del siglo $\mathrm{xx}$, cuando se dieron manifestaciones y luchas sociales en busca de mejorar las condiciones laborales, tangibles en las constantes huelgas que se originaron en el Atlántico costarricense. En 1934 se presentó la huelga más prolongada y significativa, en la que Lyra fue pilar en la logística y el mantenimiento en pie del movimiento huelguístico, lo que demuestra el compromiso de la autora no solo en la adopción de una literatura marxista sino en la práctica misma, luchando por los derechos de esas personas explotadas que retrató en «Bananos y hombres».

Los mundos antagónicos que representa la autora a lo largo del relato se refieren a dos grupos sociales incompatibles. Por un lado, la miseria de los trabajadores de las bananeras y por otro la riqueza que se genera producto de la explotación, así como la asignación simbólica de los espacios que cada grupo debía ocupar, en la división social implementada por la UFCo, donde cada cual tiene su función y posición, la cual no debe transgredirse. La obra ofrece la posibilidad de diferentes miradas, que trasciendan la relación literatura-historia, para un análisis que posicione un diálogo entre las dos disciplinas, acorde con sus dimensiones analíticas y representaciones, en el sentido de que la literatura funciona como fuente para el historiador, mientras que la historia puede ser literalizada. Por tanto, se abre una puerta de intercambio interdisciplinario que (aun con las diferencias en los utillajes teórico- metodológicos) ofrece oportunidades de análisis. La obra de Lyra representa un parteaguas de los modelos representacionales tradicionales a su vez, rescata desde lo ficcional la historia de los de abajo amparada en la militancia de la autora, que a la postre le valió su destierro. 
En suma, el relato lleva a la añeja discusión de lo histórico en la literatura; como un aspecto más amplio, la forma en que el texto reconstruye procesos históricos, y las razones mismas que llevan a las escritoras y escritores a recurrir a la naturaleza histórica en sus escritos. Sin que se ponga en duda la riqueza de esta práctica mostrada en el caso de Lyra, también está presente en novelas como $E l$ señor Presidente de Miguel Ángel Asturias, La isla de los hombres solos de Jorge León Sánchez, y Cruz de olvido de Carlos Cortés, en que se toman hechos históricos para la representación ficcional de la obra literaria. Permite acercarse al mundo del Atlántico costarricense y centroamericano durante la primera mitad del siglo xx. Por medio de la literatura, se puede comprender el contexto histórico y entrever la cotidianidad de aquellos hombres, mujeres y niños, sumergidos en la miseria. Lyra tuvo una visión holística en la construcción de la trama de la obra; contempló distintos miembros de una familia de la década de 1930, ante un enclave bananero. Esta concepción se vio sustentada por su militancia política, que le permitió comprender las condiciones en las que vivían los trabajadores de los enclaves, sumada a su afiliación a los movimientos antiimperialistas que lucharon contra las injerencias de las compañías bananeras en Centroamérica. 
